\title{
Investigation of the Tubular and Cylindrical Billets Stamping by Rolling Process with the Use of Computer Simulation
}

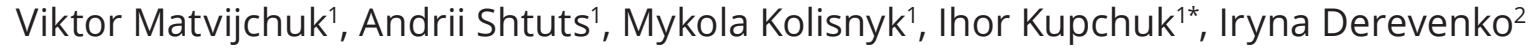 \\ ${ }^{1}$ Faculty of Engineering and Technology, Vinnytsia National Agrarian University, 21000 Vinnytsia, 3 Sonyachna Str., Ukraine \\ 2 Institute of Civil Engineering and Building Systems, Lviv Polytechnic National University, 79013 Lviv, 12 Stepan Bandera Str, Ukraine \\ * Corresponding author, e-mail: kupchuk.igor@i.ua
}

Received: 27 May 2021, Accepted: 23 October 2021, Published online: 08 December 2021

\begin{abstract}
Forming of blanks during stamping by rolling (RS) is possible according to technological schemes of deposition, landing, direct and reverse extrusion, distribution and compression, etc. Controlling the relative position and shape of the deformed tool allows you to control the direction of flow of the workpiece material and the nature of its formation, as well as the stress-strain state of the material. The complexity and versatility of RS processes necessitate computer modeling for sound management of basic technological parameters. Physical experimental as well as computer modeling of the RS process in the DEFORM-3D software package was performed in the work. According to the results of computer simulation, the distribution of deformation components, stresses and temperatures in the deformed workpiece area was obtained, and using the Cockroft-Latham criterion, the destruction of metals during cold deformation was also predicted.

Physical modeling of the SR process on lead blanks confirmed the nature of their deformation, obtained by computer simulation. And the analysis of the stress-strain state of the material based on the results of measurements of the deformed grid confirmed the validity of the appointment of boundary conditions in computer simulation.

This approach is suitable for modeling by the method of SR of any metal models, for which it is necessary to know their mechanical characteristics, including boundary deformation curves.
\end{abstract}

Keywords

rolling stamping, computer process modeling, DEFORM-3D, stress-strain state, shaping, damage accumulation, failure prediction

\section{Introduction}

The purpose of modeling: is to analyze the stress-strain state (SSS), the nature of the shape of the pipe blanks and predict their destruction in the process of stamping by rolling (SR), determining the energy parameters of the process and the geometry of the deforming tool [1, 2].

Experimental research in real production has a number of disadvantages: high energy consumption, impossibility or difficulty of mobile change of process parameters in wide ranges, probability of accident and equipment failure [3]. The advantage of computer simulation is that the results of the study can be obtained directly on the computer [4, 5].

RS processes have become increasingly developed and widespread recently. The uniqueness of this method is that it allows implementing more patterns of traditional stamping under conditions of local deformation [6]. The deformation zone and favorable deformation conditions at the contact between the tool and the billet ensure significant reduction in the deformation force and equipment power as compared to traditional stamping [7, 8]. This allows cold pressing of steels and alloys to obtain products of complex profile with developed thin-walled elements, which is difficult to do using other methods of pressure metal treatment (PMT).

Particularly advanced technological capabilities characterize the PS method, in which deformation of axial-symmetric rotating tubular billet is performed using rolls (cylindrical or conical) located at billet butts [9]. This method allows to plastically deform the billets according under technological patterns of settling, upsetting and flanging of outer and inner flanges, direct and reverse extrusion, expansion and compression, and others.

Location of treated billet's axis at an adjustable angle relative to the deforming tool's axis and the possibility of their relative mutual displacement in contact plane 
allow to significantly localize the deformation zone and reduce deformation forces using these techniques $[8,10]$. Management of active friction forces at the contact between the roll and the billet contributes to widening of technological capabilities and billet precision. Fig. 1 shows the billets obtained by RS method using different technological patterns.

The variety of RS technological patterns confirms the complexity of this process, this necessitating its study by simulation modeling.

The process of tubular billets' RS between the rigid support ring (matrix) and the conical roll was studied using modeling in DEFORM-3D software package.

DEFORM-3D software package has built-in means of prediction of destruction during cold deformation. The "default" criterion is Cockroft-Latham criterion calculated using formula [11]:

$$
D \int_{0}^{\varepsilon^{-}} \frac{\sigma^{*}}{\sigma_{u}}=d \bar{\varepsilon}_{u},
$$

$\sigma^{*}$ means maximum primary stress; $\sigma_{\mathrm{u}}$ means Mises stress intensity; $d \bar{\varepsilon}_{u}$ means accumulation of deformations intensity.

Papers [2, 12] showed that accumulated deformation at the time of destruction depends to the maximum extent on stress state parameter $\eta$. Stress state parameter $\eta$ is determined using expression $[12,13]$ :

$\eta=\frac{I_{1}\left(T_{\sigma}\right)}{\sqrt{3 \cdot I_{2}\left(D_{\sigma}\right)}}=\frac{\sigma_{1}+\sigma_{2}+\sigma_{3}}{\sigma_{8}}$,

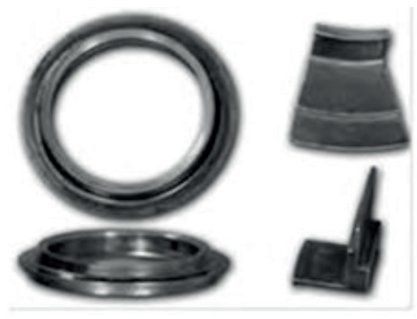

a

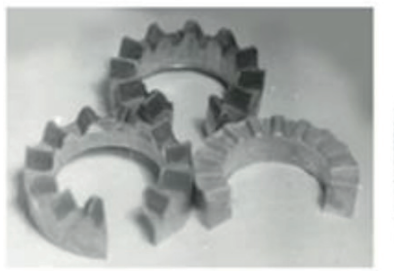

c

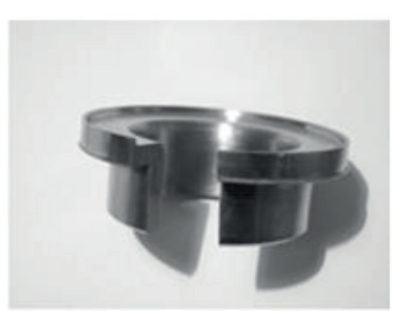

b

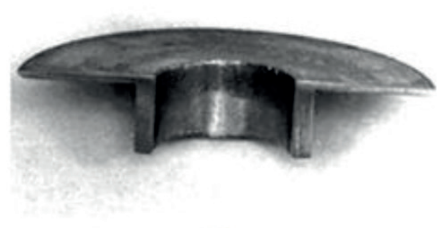

d
Fig. 1 a) Billets made by RS method under technological patterns; b) combined with upsetting and reverse extrusion; c) - direct extrusion; d) - flanging where $\sigma_{1}, \sigma_{2}, \sigma_{3}$ means primary stresses; $\sigma_{\mathrm{u}}$ means stress intensity.

Cockroft-Latham criterion satisfactorily describes the accumulation of damage in the tensile zone of metal $(\eta=+1)$, being "by default" criterion in DEFORM-3D software package.

In case of more complicated deformation patterns, V. A. Ogorodnikov's scalar criterion is used, which criterion takes into account nonlinear damage accumulation and various ways of metal loading $[12,14]$ :

$$
\psi=\int_{0}^{e_{u}^{*}}\left(1+a \cdot \operatorname{arctg} \frac{d \eta}{d e_{u}}\right) \cdot \frac{e_{u}^{\operatorname{a\cdot arctg} \frac{d \eta}{d e_{u}}}}{\left[e_{p}\left(\eta\left(e_{u}\right)\right)\right]^{1+\operatorname{ararctg} \frac{d \eta}{d e_{u}}}} d e_{u} \leq 1 .
$$

In cases of complex, particularly non-monotonic deformation, tensor approach is the most suitable one to assess metal deformability, according to which approach the destruction condition has the following form:

$\psi_{i j} \cdot \psi_{i j}=1$.

Tensor-nonlinear model of damage accumulation was developed by V. M. Mikhalevich, having the following form [15]:

$\psi_{i j}=\int_{0}^{e_{u}}\left(A \beta_{i j}+B\left(\beta_{i k} \beta_{k j}-\frac{1}{3} \delta_{i j}\right)\right) d e_{u}$,

where:

- $A$ and $B$ mean some functions;

- $B_{i k} B_{k j}$ means tensor square $B_{i j}$;

- $\delta_{i j}$ means unit tensor: $\delta_{i j}=1$ at $i=j$ and $\delta_{i j}=0$ at $i \neq j$.

Studied physical and simulation billets were modeled to ensure $h / d=2.49998$ ratio [16]. The material is plastic lead of Lead grade [70-600F (20-300C)] selected from the material library available in the software package and served as the material model during hot deformation. Simulated sample was divided into a set of finite elements with particular binding. That is, a finite element grid with the following parameters was simulated on the sample: Lead-grade lead [70-600F (20-300C)], grid type - volume, finite element type - tetrahedron, number of elements - 20,000, number of nodes $-3,396$, number of surface polygons - 3,760, minimum element size $-3.51497 \mathrm{~mm}$, maximum element size $-7.02994 \mathrm{~mm}$.

Flow theory relations were used as physical dependencies between stresses and deformations, material strengthening was isotropic and the structure was normalized. The following friction parameters were selected: type - shear, 
coefficient -0.3 . The main tool's (roll's) movement speed $0.8 \mathrm{~mm} / \mathrm{s}$, the drive tool's rotation $-8 \mathrm{rpm}$. RS was carried out prior to the stage of sample height's reaching $50 \mathrm{~mm}$, with the initial height of $100 \mathrm{~mm}$. Deformation time - $500 \mathrm{~s}$. Deformation process temperature is $20^{\circ} \mathrm{C}$. Process calculation in the software package is divided into 400 steps.

The technique of boundary conditions selection in DEFORM-3D software package during numerical simulation of tubular billets RS process.

Fig. 2 a) and b) show the experimental models of rigid conical roll and rigid support ring (matrix).

As a result of modeling, obtained were the patterns of billet shape change during deformation (Fig. 3), of accumulated deformation sample's volume distribution (Fig. 4), of stress intensity (Fig. 5) and accumulated damage (Fig. 6) [3].

The damage is calculated in DEFORM-3D software package according to Cockroft-Latham model [4]:

$\int_{0}^{\varepsilon_{u}} \frac{\bar{\sigma}_{\max }}{\sigma_{u}} \cdot d \varepsilon_{u}=C$

where $\bar{\sigma}_{\text {max }}$ means maximum primary tensile stress; $\sigma_{u}$ means Mises stress intensity; $C$ means material constant.

To obtain and analyze the results of SDS modeling in billet's meridional section, we used special commands in DEFORM-3D postprocessor. Obtained results are shown in Figs. 7 and 8, and Table 1.
Deformation trajectories shown in Fig. 9 generated in Microsoft Office Excel, Maple application package based on tabular values of stress components and accumulated deformation obtained in DEFORM-3D package.

The precision of determining the boundary conditions during numerical simulations was enhanced in accordance with the results of experimental-analytical modeling of tubular billets' SDS during RS.

The technique's essence is to select such parameters of numerical simulations that would lead to obtaining of deformation trajectories:

$\varepsilon_{u}=\varepsilon_{u}(\eta)$,

for the side surface point identical to the results of experimental-analytical modeling [17].

During modeling, DEFORM-3D software package offered options of sample type selection: solid body, plastic, elastic, and elastoplastic [4].

The grid of finite elements was set by the following parameters: the grid type is three-dimensional, the finite element type is tetrahedron and the number of elements varied within the range of $-20000 \div 26229$. Computational experiments have shown that varying the number of elements within the range of $20000 \div 26229$ does not significantly affect the modeling results, although fluctuations in diagrams of deformation, stress and deformation
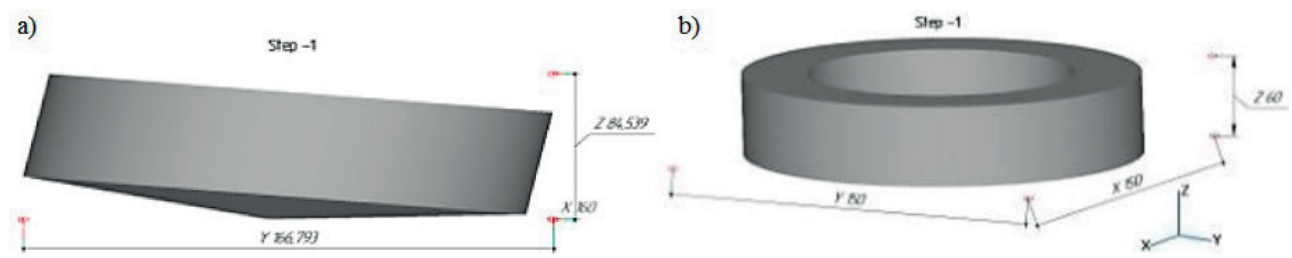

Fig. 2 a) Presented experimental model of rigid conical roll and; b) experimental model of rigid support ring (matrix)

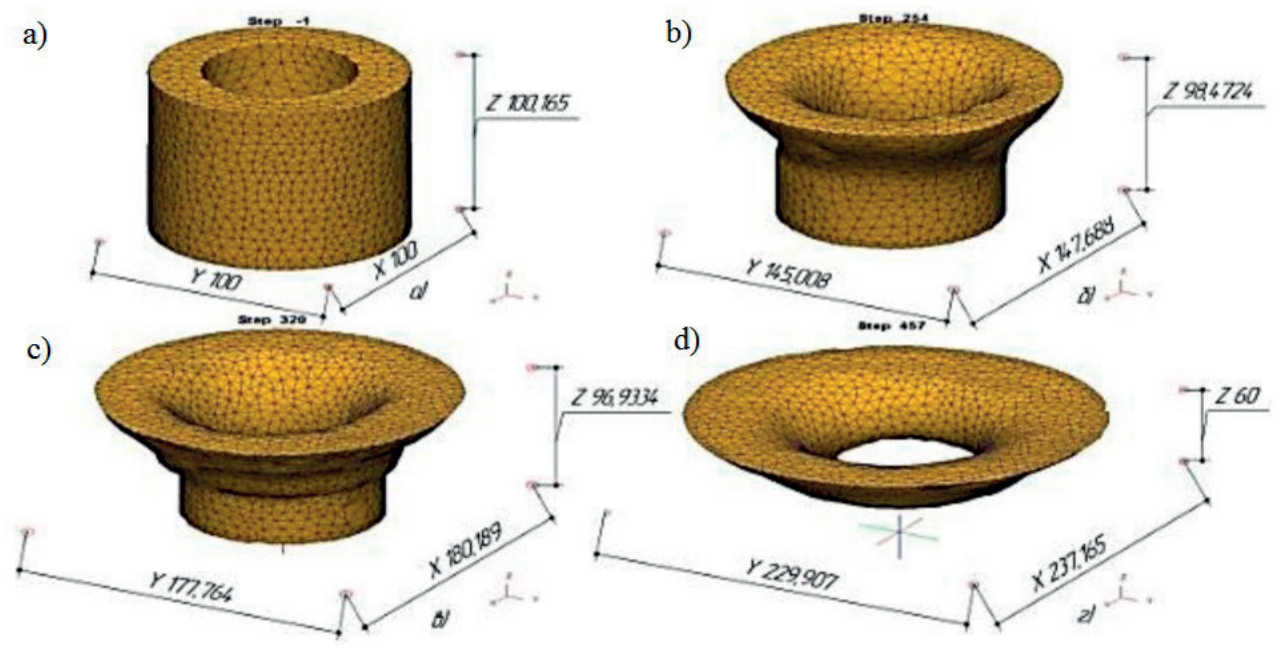

Fig. 3 Tubular billet's shape change during RS: a) the initial stage; b) at the $254^{\text {th }}$ step of RS; c) at the $320^{\text {th }}$ step of RS; d) the final step of deformation 


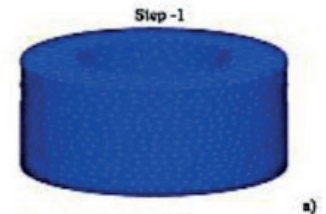

c)

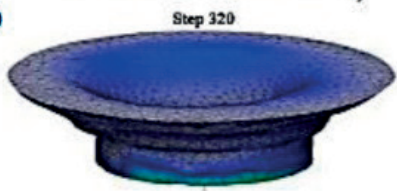

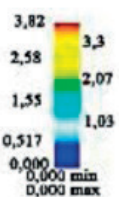

\begin{tabular}{r|r}
3,32 & 2,82 \\
2,51 & 2,30 \\
1,68 & 1,29 \\
0,878 & 0,472 \\
0,492 & 0,02
\end{tabular} b)

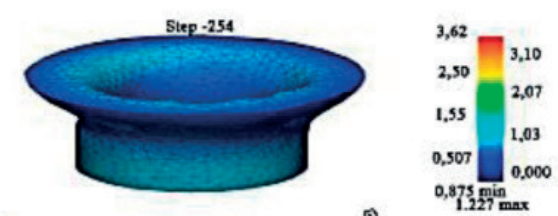

d)

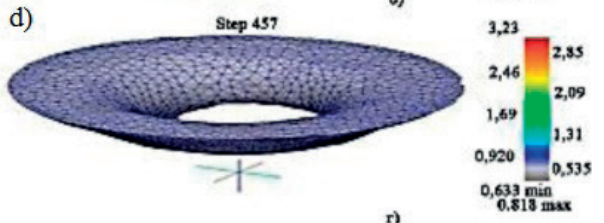

Fig. 4 Accumulated deformation distribution across the tubular billet volume during RS: a) the initial stage; b) at the $254^{\text {th }}$ step of RS; c) at the $320^{\text {th }}$ step of RS; d) the final step of deformation

a)

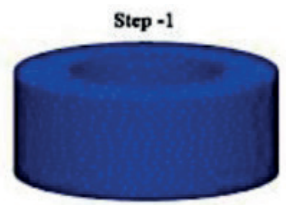

c)

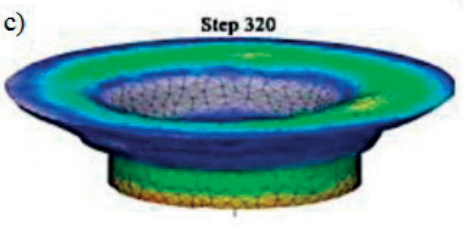

a)

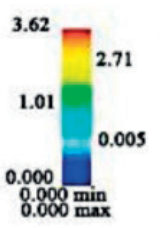

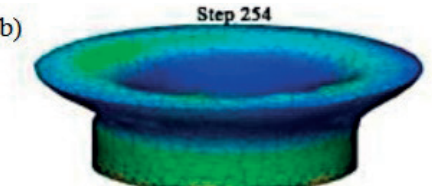

d)
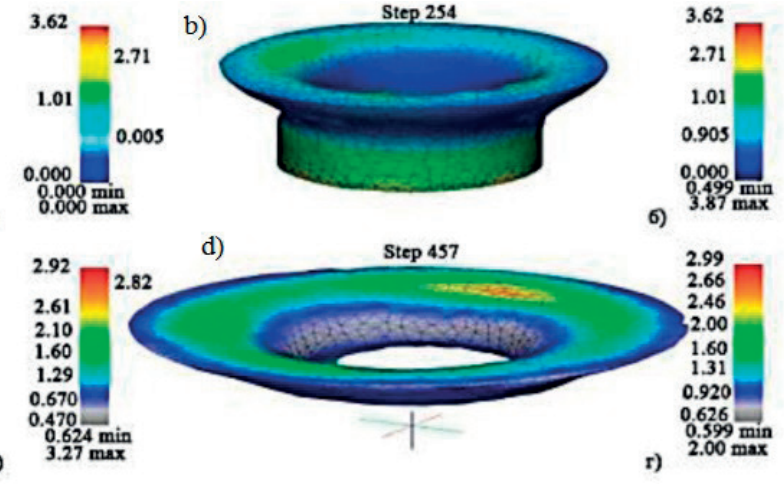

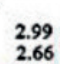

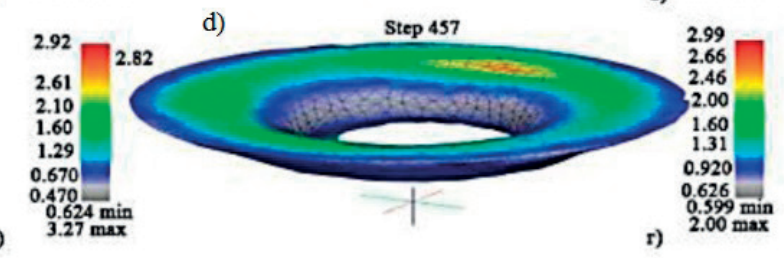

Fig. 5 Stress intensity distribution across the tubular billet volume during RS: a) the initial stage; b) at the $254^{\text {th }}$ step of RS; c) at the $320^{\text {th }}$ step of RS; d) the final step of deformation

a)

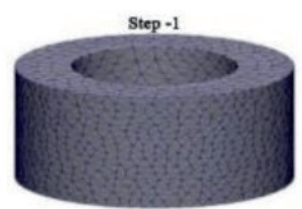

c)

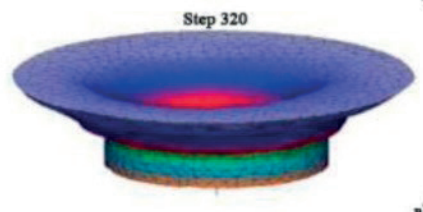

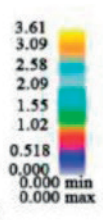

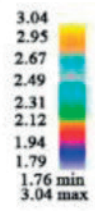

b)

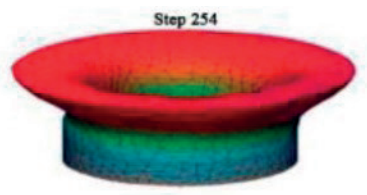

d)

Step 457

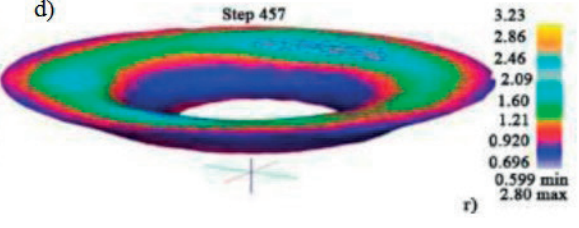

Fig. 6 Damage accumulation distribution across the tubular billet volume during RS: a) the initial stage; b) at the $254^{\text {th }}$ step of RS; c) at the $320^{\text {th }}$ step of RS; d) the final step of deformation

a)

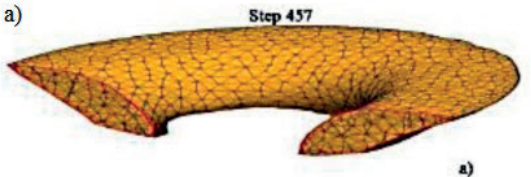

4)

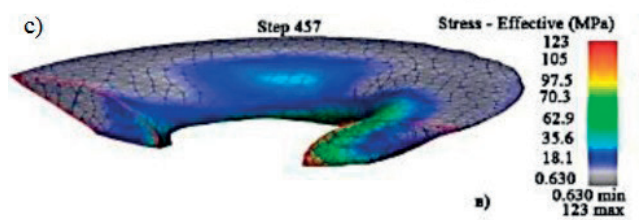

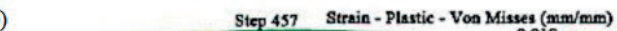

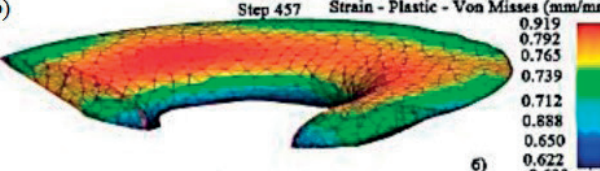

Step 457

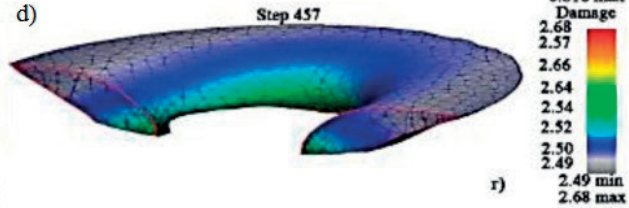

Fig. 7 a) Shape change; b) and accumulated deformation distribution across the billet's meridional section at the final RS stage; c) stress intensity; d) accumulated damage 


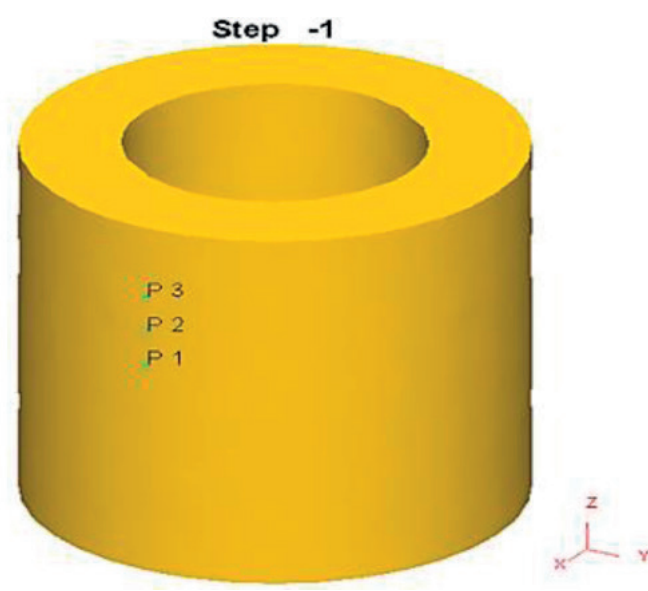

Fig. 8 Location of tubular billets' studied points during numerical simulation of RS

\begin{tabular}{lccc}
\multicolumn{4}{l}{ Table 1 The coordinates values of the studied points of tubular billets } \\
\hline No. of the point & $\mathrm{X}, \mathrm{mm}$ & $\mathrm{Y}, \mathrm{mm}$ & $\mathrm{Z}, \mathrm{mm}$ \\
\hline 1 & 50 & 0 & 70 \\
2 & 50 & 0 & 80 \\
3 & 50 & 0 & 90 \\
4 & 0 & 0 & 40 \\
\hline
\end{tabular}

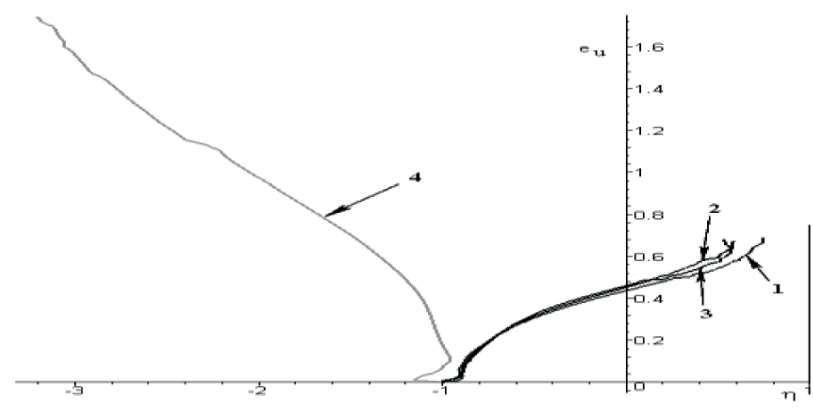

Fig. 9 Deformation trajectories for different points of tubular billet generated using the results of numerical simulation in DEFORM -3D software package

trajectories decrease, with calculation time at the same time increasing 10 times - from 18 minutes to about 18 hours. Therefore, the following parameter values were used during numerical modeling: the number of elements was taken as equal to 20,000, minimum element size $3.100506 \mathrm{~mm}$, the ratio between the maximum and minimum element size was 2. DEFORM-3D adjusted this value to 19976 , having calculated the number of nodes -2484 , the number of surface polygons -4016 .

Flow theory relations were used as physical dependencies, material strengthening was isotropic. Friction conditions were deemed corresponding to shear type.

RS was carried out prior to the stage of main tool's relocation by $50 \mathrm{~mm}$. Deformation time - $500 \mathrm{~s}$. Deformation process temperature is $20^{\circ} \mathrm{C}$. Process calculation in the software package is divided into 457 steps. Technique for selection of boundary conditions in DEFORM 3D software package during numerical modeling of RS process.

The results of application of the technique for improving the boundary conditions' determination accuracy during 3D modeling using the results of experimental-analytical modeling of tubular billet SDS during RS in accordance with real conditions of shape change is illustrated in Figs. 10 to 12.

For clear comparison between modeling results and experimental research, Fig. 10 shows the billet during the experiment and as a result of modeling. It follows from the deformation trajectories shown in Fig. 12 and generated based on the results of experimental research and numerical modeling of the tubular billet that the discrepancy between them does not exceed the natural error of experimental data scattering.

Therefore, to obtain the results of numerical modeling adequate to the real conditions of deformation, an approach and method of improving the accuracy of determining the boundary conditions during numerical modeling using the results of experimental-analytical modeling of stress-strain state of the tubular billets at stamping by rolling is proposed, which lies in the fact, that the results of experimental research are taken as a principle of determining the boundary conditions of the mentioned system for 3D modeling of the sample with provision of the necessary conditions of straining [11].

To determine the specificities of deformation process, to study stress-deformation state (SDS) and the deformability of cylindrical tubular billets during RS, as well as the basis of approximations of dependencies between deformation components, experimental study of RS process was carried out [1].

In Figs. 13 to 15, the general view of the equipment to be used in studies is shown [17].

According to the experimental-analytical approach, whereby the stress-strain state and boundary conditions are investigated, based on the results of measurements of dimensions $a$ and $b$ of the distorted coordinate grid at the intermediate stages of straining, the relationship between axial and circular deformations of the lateral surface of the cylindrical sample at stamping by rolling:

$$
\varepsilon_{z}=f\left(\varepsilon_{\varphi}\right),
$$

is established in the form of a prescribed table function.

Deformations and are determined using the expressions [11]:

$\varepsilon_{z}=\ln \left(\frac{b}{b_{0}}\right) ; \quad \varepsilon_{\varphi}=\ln \left(\frac{a}{a_{0}}\right)$. 
a)

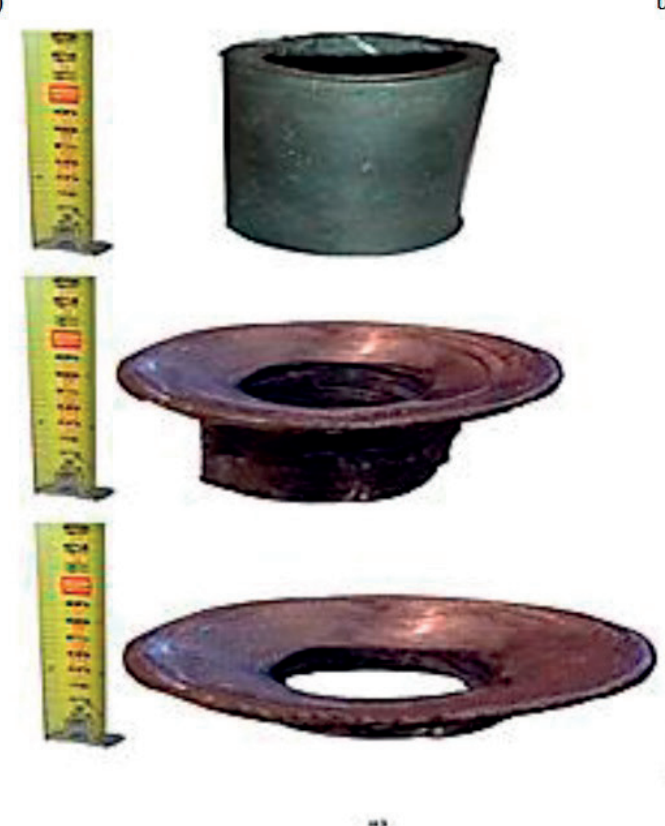

b)

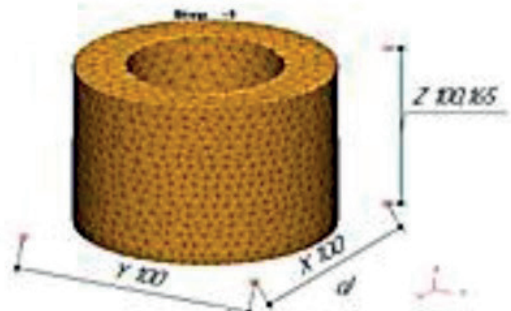

Fig. 10 Stamping by rolling of the lead billet no. 5: a) experimental study; b) modeling in DEFORM-3D

a)
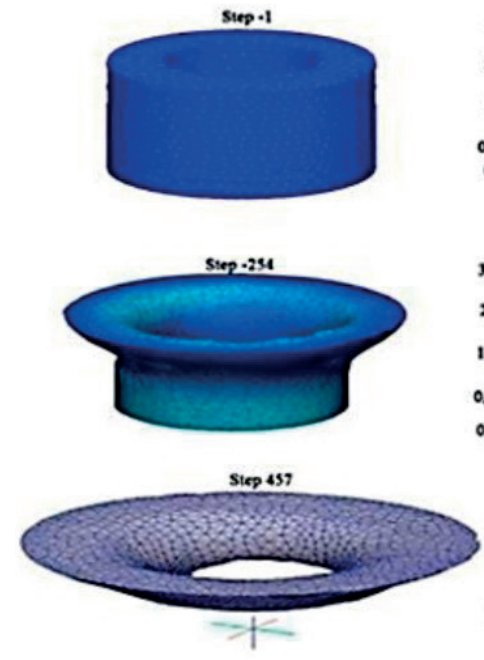
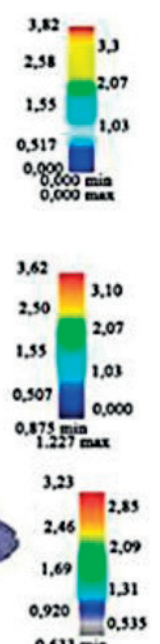

b)
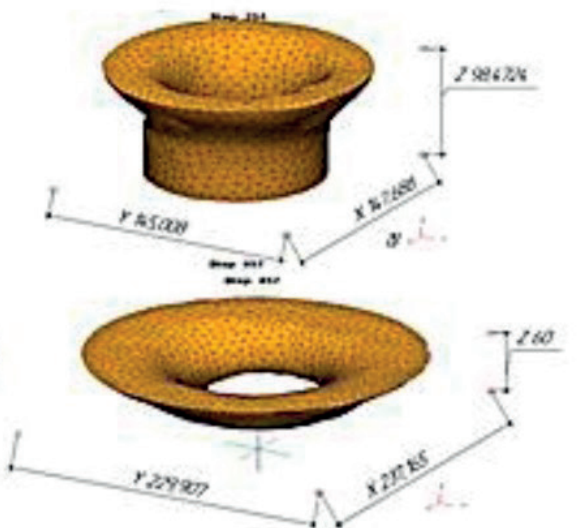

Fig. 11 Distribution of the cumulative deformation: a) of the stress intensity; b) during simulation of the stamping by rolling process of the lead sample no. 5

On the billet's side surface (Fig. 13), by changing the size of which under formulas (3) the values of circumferential and axial logarithmic deformations are determined.

Determination of billet material's VAT using experimental method allows adjusting the calculations in DEFORM-3D software package by adjusting the boundary conditions (see Figs. 16 and 17).

\section{Conclusions}

The stress-strain state and the nature of deformation of pipe blanks in the process of stamping by rolling (SR) are analyzed.
Experimental studies in real production have a number of disadvantages: high energy consumption, impossibility or difficulty of mobile change of process parameters in a wide range, the probability of accident and equipment failure. Therefore, the simulation of the rolling stamping process was performed and the results were compared with experimental studies.

Computer simulation of the process of SR pipe billets was performed using the DEFORM-3D application package, based on the use of the element method, in different variants. 


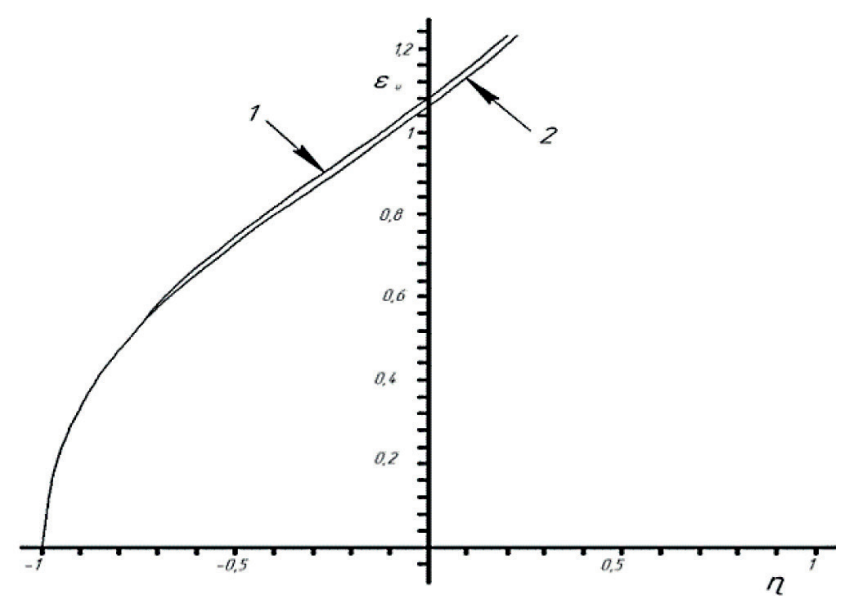

Fig. 12 Deformation trajectories of the lateral surface of the lead billet no. 5: 1 - experimental study; 2-modeling in the DEFORM-3D software package
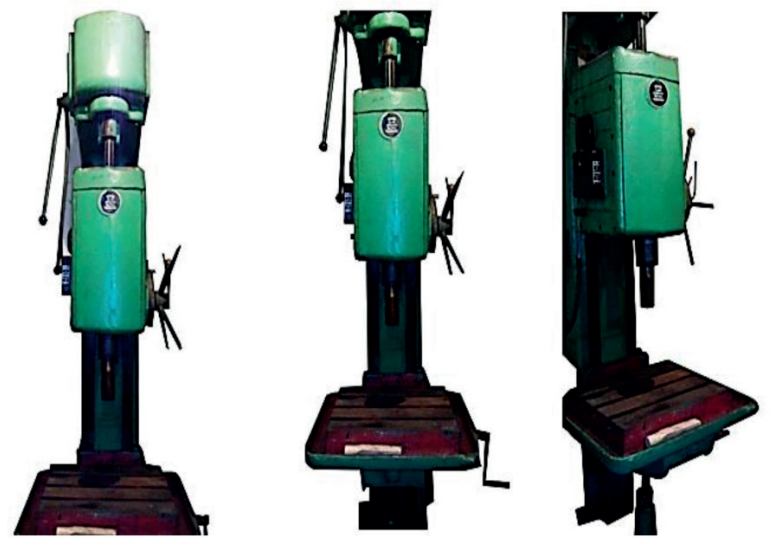

Fig. 13 Vertical drilling machine 2A-135 used in studying the stamping by rolling process
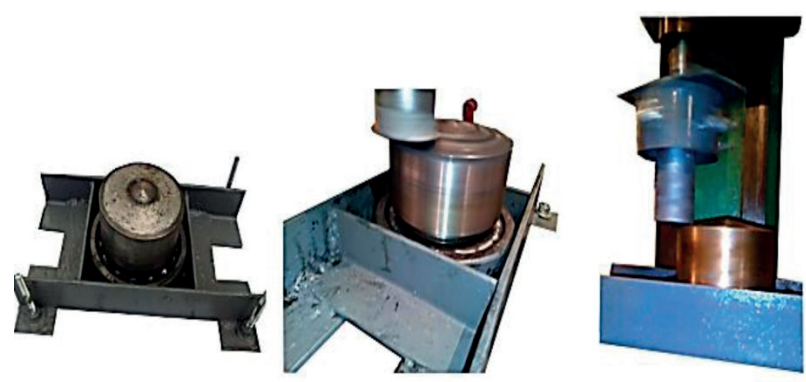

Fig. 14 General view of the auxiliary device SRP-1 for the study of the stamping by rolling process

Computer modeling determined: SSS parameters, use of plasticity resource, nature of shape change of pipe blanks and final product geometry, distribution of specific forces on the workpiece contact surface with the roll, as well as dependence of SR process effort on billet material movement.

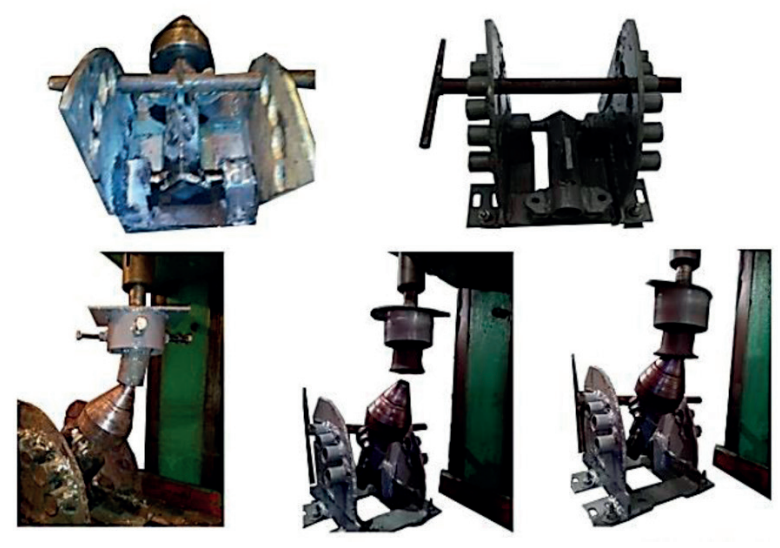

Fig. 15 General view of the auxiliary device SRP-2 used for the stamping by rolling process study

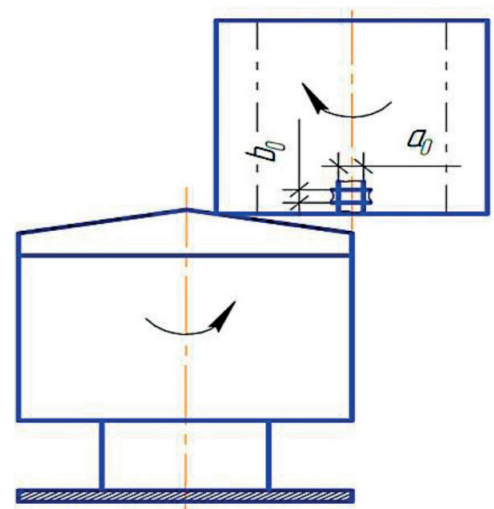

Fig. 16 Dimensional grid for experimental determination of strains (ПШО-1)

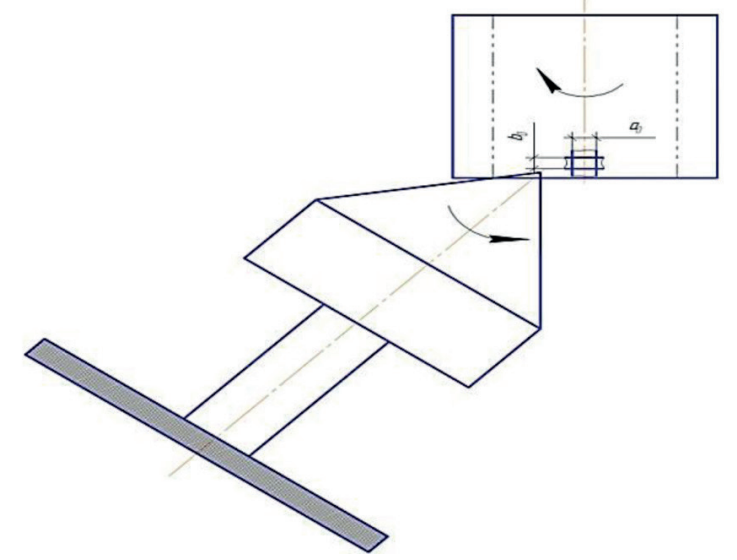

Fig. 17 Dimensional grid for experimental determination of strains (ПШО-2)

Further development of processes is possible by developing new technological schemes based on the analysis of deformation kinematics and assignment of favorable technological parameters taking into account their impact on SSS and deformability of the workpiece material. 


\section{References}

[1] Matvyichuk, V. A., Alyev, Y. S. "Совершенствование процессов локальной ротационной обработки давлением на основе анализа деформируемости металлов: монография" (Improvement of the rotary machining process based on the analysis of the deformability of metals: Monograph), DGMA, Kramatorsk, Ukraine, 2009. (in Ukrainian)

[2] Sivak, R. "Evaluation of metal plasticity and research on the mechanics of pressure treatment processes under complex loading", Eastern-European Journal of Enterprise Technologies, 6(7), pp. 34-41, 2017.

https://doi.org/10.15587/1729-4061.2017.115040

[3] Shtuts, A., Kolisnyk, M., Vydmysh, A., Voznyak, O., Baraban, S., Kulakov, P. "Improvement of Stamping by Rolling Processes of Pipe and Cylindrical Blades on Experimental Research", Key Engineering Materials, 844, pp. 168-181, 2020.

https://doi.org/10.4028/www.scientific.net/kem.844.168

[4] Markov, O. E., Aliiev, I. S., Aliieva, L. I., Hrudkina, N. S. "Computerized and physical modeling of upsetting operation by combined dies", Journal of Chemical Technology and Metallurgy, 55(3), pp. 640-648, 2020.

[5] Kupchuk, I. M., Solona, O. V., Derevenko, I. A., Tverdokhlib, I. V. "Verification of the mathematical model of the energy consumption drive for vibrating disc crusher", Inmateh - Agricultural Engineering, 55(2), pp. 111-118, 2018.

[6] Shtuts, A., Kolisnyk M., Yavdyk, V. "Improvement of processes of rolling stamping on the basis of investigation of technological parameters on the mechanics of workpieces' formation", MOTROL - Commission of Motorization and Energetics in Agriculture, 20(1), pp. 19-25, 2018.

[7] Ogorodnikov, V. A., Dereven'ko, I. A., Sivak, R. I. "On the Influence of Curvature of the Trajectories of Deformation of a Volume of the Material by Pressing on Its Plasticity Under the Conditions of Complex Loading", Materials Science, 54(3), pp. 326-332, 2018.

https://doi.org/10.1007/s11003-018-0188-X

[8] Solona, O., Derevenko, I., Kupchuk, I. "Determination of Plasticity for Pre-Deformed Billet", Solid State Phenomena, 291, pp. 110-120, 2019.

https://doi.org/10.4028/www.scientific.net/SSP.291.110

[9] Aliev, I., Zhbankov, Y., Martynov, S. "Forging of shafts, discs and rings from blanks with inhomogeneous temperature field", Journal of Chemical Technology and Metallurgy, 51(4), pp. 393-400, 2016.
[10] Ogorodnikov, V. A., Savchinskij, I. G., Nakhajchuk, O. V. "Напряженно-деформированное состояние при формировании внутреннего шлицевого профиля методом обжатия на оправке" (Stressed-strained state during forming the internal slot section by mandrel reduction), Tyazheloe Mashinostroenie (Russian Journal of Heavy Machinery), 12, pp. 31-33, 2004. (in Russian)

[11] Sree, L. G., Matvijchuk, V., Rubanenko, O., Branitskyi, Y. "Justification and development of methods building curves boundary deformation of metals", Materials Today: Proceedings, 38(Part 5), pp. 3337-3344, 2021.

https://doi.org/10.1016/j.matpr.2020.10.243

[12] Ogorodnikov, V. A., Grechanyuk, N. S., Gubanov, A. V. "Energy Criterion of the Reliability of Structural Elements in Vehicles", Materials Science, 53(5), pp. 645-650, 2018. https://doi.org/10.1007/s11003-018-0119-x

[13] Kovbasa, V., Solona, O., Deikun, V., Kupchuk, I. "Functions derivation of stresses in the soil and resistance forces to the motion of a plough share for cavity creation", UPB Scientific Bulletin, Series D, 83(3), pp. 305-318, 2021.

[14] Ogorodnikov, V. A., Arkhipova, T. F. "Prediction of the Mechanical Properties of Metals After Cold Pressing", Materials Science, 55(1), pp. 63-68, 2019. https://doi.org/10.1007/s11003-019-00252-9

[15] Mikhalevich, V. M., Lebedev, A. A., Dobranyuk, Y. V. "Modeling of plastic deformation in a cylindrical specimen under edge compression", Strength of Materials, 43(6), pp. 591-603, 2011. https://doi.org/10.1007/s11223-011-9332-7

[16] Trembach, B., Grin, A., Turchanin, M., Makarenko, N., Markov, O., Trembach, I. "Application of Taguchi method and ANOVA analysis for optimization of process parameters and exothermic addition $(\mathrm{CuO}-\mathrm{Al})$ introduction in the core filler during self-shielded flux-cored arc welding", The International Journal of Advanced Manufacturing Technology, 114(3-4), pp. 1099-1118, 2021. https://doi.org/10.1007/s00170-021-06869-y

[17] Allieva, L., Hrudkina, N., Aliiev, I., Zhbankov, I., Markov, O. "Effect of the tool geometry on the force mode of the combined radial-direct extrusion with compression", Eastern-European Journal of Enterprise Technologies, 2(1), pp. 15-22, 2020. https://doi.org/10.15587/1729-4061.2020.198433 